\title{
Qualidade de pequis fatiados e inteiros submetidos ao congelamento
}

\author{
Quality of whole and sliced pequi submitted to freezing
}

\author{
Brígida Monteiro Vilas Boas ${ }^{\mathrm{I}}$ Gilma Auxiliadora Santos Gonçalves ${ }^{\mathrm{II}}$ Juliana Alvarenga Alves ${ }^{\mathrm{II}}$ \\ Juliana Maria Valério ${ }^{\text {III }}$ Tatielle Custódio Alves ${ }^{\text {III }}$ Luiz José Rodrigues ${ }^{\text {IV }}$ Roberta Hilsdorf Piccoli ${ }^{\text {III }}$ \\ Eduardo Valério de Barros Vilas Boas ${ }^{\text {III }}$
}

\section{RESUMO}

O trabalho foi realizado com o objetivo de avaliar a qualidade de pequis inteiros e fatiados submetidos ao congelamento por ar forçado durante 12 meses de armazenamento. Os frutos foram selecionados, lavados, sanitizados, descascados, branqueados, resfriados, fatiados e mantidos inteiros, acondicionados em saco de polietileno de baixa densidade, congelados em túnel de congelamento com ar forçado por 6 horas $\left(-18^{\circ} \mathrm{C}\right)$ e armazenados em congelador doméstico a $-18^{\circ} \mathrm{C}\left( \pm 2^{\circ} \mathrm{C}\right)$, por 12 meses. A cada três meses, foram realizadas as seguintes análises: $p H$, acidez titulável, sólidos solúveis, firmeza, valores $L^{*}, a^{*}, b^{*}, h^{\circ}$ e $C^{*}$, carotenoides totais, $\beta$-caroteno, vitamina $C$, índice de peróxidos, coliformes a $35^{\circ} \mathrm{C}$ e a $45^{\circ} \mathrm{C}$ e pesquisa de Salmonella sp. $O$ congelamento do pequi inteiro é mais efetivo em preservar os teores de sólidos solúveis e vitamina $C$ e os valores $L^{*} e b^{*}$ quando comparado com o do pequi fatiado. O tempo de armazenamento de 12 meses determina redução nos valores $a^{*}, b^{*}, C^{*}$ e de firmeza e nos teores de sólidos solúveis, carotenoides totais, $\beta$-caroteno e vitamina $C$ em pequi congelado, independentemente do corte usado. O pequi congelado não sofre o processo de rancificação oxidativa nem alterações no $\mathrm{pH}$, nos teores de acidez titulável e na tonalidade de cor $\left(h^{\circ}\right)$. Pequis congelados, na forma inteira e fatiada, são considerados seguros microbiologicamente durante 12 meses de armazenamento, não oferecendo riscos à saúde dos consumidores, desde que obedecidas à cadeia de frio e às boas práticas de fabricação.

Palavras-chave: Caryocar brasiliense Camb., armazenamento, conservação, qualidade.

\begin{abstract}
This research was carried out aiming to evaluate the quality of pequi fruit (whole and sliced) after forced-air freezing storage during 12 months. The fruits were submitted to treatments as follows: selecting, washing, sanitizing, peeling, blanching, cooling, and slicing or not. After that, the fruits were storage using low density polyethylene bags and submitted to forced-air freezing $\left(-18^{\circ} \mathrm{C}\right)$ for 6 hours and stored in freezer at the same temperature $\left( \pm 2^{\circ} \mathrm{C}\right)$ for 12 months. Each three months were measured: $\mathrm{pH}$, titratable acidity, soluble solids, firmness, color ( $L^{*}, a^{*}, b^{*}, h^{\circ}$ and $C^{*}$ values), total carotenoids, $\beta$-carotene, vitamin $C$, peroxide value, coliforms at $35^{\circ} \mathrm{C}$ and $45^{\circ} \mathrm{C}$ and Salmonella sp. Frozen whole pequi fruits is more effective in preserving the soluble solids and vitamin $C$ contents and $L^{*}$ and $b^{*}$ values as compared to the sliced pequi fruits. The freezing-storage time reduce $a^{*}, b^{*}$ and $C^{*}$ values, firmness values, soluble solids, total carotenoids, $\beta$-carotene and vitamin $C$ contents of the pequi fruit, whole or sliced. Pequi fruit frozen is not affected by rancidity oxidative process, and also does not alter the $\mathrm{pH}$, titratable acidity, and color $\left(h^{\circ}\right)$. Pequi fruit frozen and stored during 12 months are considered microbiologically safe, not offering health risks to consumers, since that the good practices of manufacture are realized and the freezing and stored process are performed correctly.
\end{abstract}

Key words: Caryocar brasiliense Camb., storage, conservation, quality.

IInstituto Federal de Educação, Ciência e Tecnologia do Sul de Minas Gerais, campus Machado, Rod. Machado-Paraguaçu, km 3, Santo Antônio, 37750-000, Machado, MG, Brasil. E-mail: brigida@mch.ifsuldeminas.edu.br. Autor para correspondência.

IIInstituto Federal de Educação, Ciência e Tecnologia, Região Sudeste-MG, Campus Barbacena, Barbacena, MG, Brasil.

IIIDepartamento de Ciência dos Alimentos, Universidade Federal de Lavras (UFLA), Lavras, MG, Brasil.

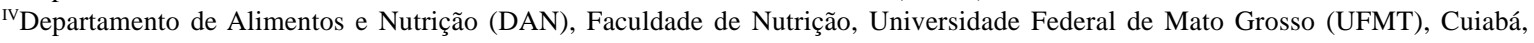
MT, Brasil. 


\section{INTRODUÇÃO}

O pequi (Caryocar brasiliense Camb.) é um fruto nativo do Cerrado Brasileiro muito apreciado pelo seu aroma e sabor exóticos e peculiares, possui alto valor nutritivo, constitui-se de fonte de proteína, lipídeo, vitamina A e minerais (VILAS BOAS, 2004).

O pequi apresenta, porém, o inconveniente de apresentar o endocarpo espinhoso aderido ao mesocarpo interno, que é a porção comestível. Parte do endocarpo espinhoso chega até mesmo a se confundir, morfologicamente, com o mesocarpo interno. A presença dos espinhos limita o consumo do pequi e sua expansão na culinária brasileira. Assim, o fatiamento do mesocarpo interno isento de espinhos aumenta a conveniência do pequi (VILAS BOAS, 2004).

O consumo e o uso do pequi ainda estão restritos à população local do cerrado, onde é explorado de forma extrativista. Na época da safra, o pequi se torna a principal fonte de renda das populações da região produtora, entretanto, há grande perda do produto, devido a sua perecibilidade e, principalmente, à falta de métodos adequados de conservação. Assim, o congelamento surge como uma alternativa para prolongar a vida de prateleira e manter a qualidade do pequi, possibilitando a sua oferta durante o ano todo e também em diferentes regiões, além de, consequentemente, expandir o fruto na culinária brasileira e agregar valor ao produto.

O congelamento é atualmente uma prática muito utilizada para a conservação de alimentos. Portanto, é importante que seja realizado de forma a preservar ao máximo as características dos alimentos e impedir o crescimento microbiano. De acordo com ALVES (1999), as modificações que ocorrem durante o armazenamento de frutos congelados podem ser físicas, químicas, bioquímicas e nutricionais, e acontecem em função de diversos fatores, tais como tempo e temperatura de congelamento e armazenamento.

GONÇALVES et al. (2010), ao estudar a qualidade do pequi proveniente do Norte de Minas Gerais, submetido ao cozimento após congelamento por diferentes métodos e tempos de armazenamento, observaram que a microestrutura celular, a vitamina $C$ (até o quarto mês) e o beta-caroteno são melhor preservados pelo método por ar forçado do que pelo congelamento por ar estático. Além disso, esses autores concluíram que a qualidade do pequi cozido após o congelamento é mais influenciada pelo tempo de armazenamento que pelo método de congelamento, sendo o congelamento eficiente para preservação da qualidade desse fruto.

Nesse sentido, o trabalho foi realizado com o objetivo de avaliar a qualidade de pequis inteiros e fatiados submetidos ao congelamento por ar forçado durante 12 meses de armazenamento.

\section{MATERIAL E MÉTODOS}

As etapas do fluxograma para a obtenção de pequi inteiro e fatiado submetido ao congelamento estão apresentadas resumidamente na figura 1.

Os pequis foram coletados em uma área de pastagem nativa com formação típica do cerrado localizada a $12 \mathrm{~km}$ do município de Itumirim, sul do estado de Minas Gerais. Os frutos do pequizeiro foram coletados na $12^{-}$semana após a abertura das flores e selecionados quanto ao tamanho, cor da casca e ausência de injúrias. Ao chegar ao laboratório, foram lavados em água corrente com detergente neutro e sanificados em solução de hipoclorito de sódio 300mg $\mathrm{L}^{-1}$, por 15 minutos e secos à temperatura de $18^{\circ} \mathrm{C}$. O caroço (pirênio) foi separado manualmente, com auxílio de facas, da casca e do mesocarpo externo, o qual foi novamente selecionado quanto à ausência de defeitos e injúrias e padronização da cor do mesocarpo interno (amarelo intenso). Em seguida, os pirênios foram submetidos ao branqueamento, que consistiu na imersão em água à temperatura de $100^{\circ} \mathrm{C}$ por 3 minutos, logo após foram resfriados em água a $18^{\circ} \mathrm{C}$.

O experimento foi conduzido em delineamento inteiramente casualizado. Os tratamentos foram dispostos por um fatorial 2x6, sendo constituído pelos fatores corte (fatiado e inteiro) e tempo de armazenamento (0, 3, 6, 9 e 12 meses). A parcela experimental foi constituída por uma embalagem contendo aproximadamente 50 e $200 \mathrm{~g}$ de pequi fatiado e inteiro, respectivamente. As análises estatísticas foram feitas com auxílio do programa Sisvar (FERREIRA, 2000).

Os pirênios foram divididos em dois lotes, sendo que o primeiro foi embalado imediatamente em saco de polietileno de baixa densidade, contendo aproximadamente 200g, e selados em seladora TecMaq AP450. O segundo lote foi cortado em fatias (tiras) usando-se faca afiada de aço inoxidável e, em seguida, aproximadamente $50 \mathrm{~g}$ de pequi fatiado foram embalados em saco de polietileno de baixa densidade e selados em seladora TecMaq AP450.

O pirênio inteiro e o fatiado, acondicionados em embalagens plásticas, foram congelados em túnel de congelamento com ar forçado por 6 horas $\left(-18^{\circ} \mathrm{C}\right)$. Após o congelamento, as embalagens plásticas foram armazenadas em congelador doméstico à temperatura de $-18^{\circ} \mathrm{C}\left( \pm 2^{\circ} \mathrm{C}\right)$ por 12 meses.

As amostras foram descongeladas na própria embalagem a cada três meses, em banho de imersão a $30^{\circ} \mathrm{C}$ por 3 e 5 minutos para o pirênio fatiado 


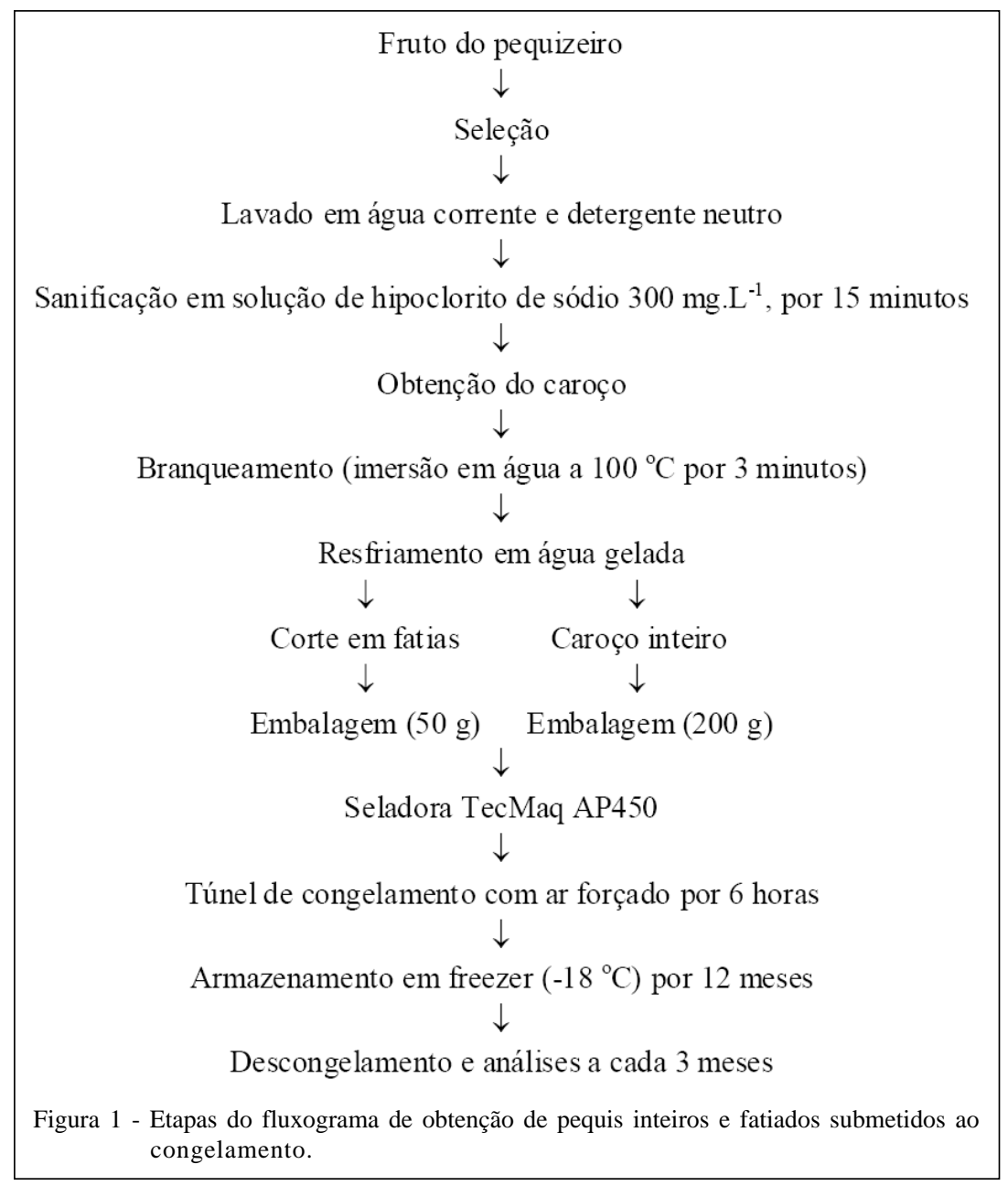

e inteiro, respectivamente, e submetidas às seguintes análises:

pH - utilizou-se pHmetro TECNAL (Tec 3MP), segundo a AOAC (2002); Acidez titulável (volume gasto, em $\mathrm{mL}$, de $\mathrm{NaOH} 0,01 \mathrm{~N}$ ) - realizada por titulação com solução de hidróxido de sódio $(\mathrm{NaOH})$ 0,01N, usando como indicador a fenolftaleína (IAL, 1985); Sólidos solúveis ( ${ }^{\circ} \mathrm{Brix}$ ) - usou-se refratômetro digital ATAGO PR-100 com compensação de temperatura automática, a $25^{\circ} \mathrm{C}$ (AOAC, 2002); Firmeza $\left(\mathrm{N} \mathrm{mm}^{-1}\right)$ - realizada na região equatorial do caroço inteiro de cada repetição, usando-se o texturômetro Stable Micro System modelo TAXT2i, com a sonda tipo agulha $\mathrm{P} / 2 \mathrm{~N}$ (2mm de diâmetro), que mediu a força de penetração desta nas amostras, numa velocidade de $5 \mathrm{~mm} \mathrm{~s}^{-1}$ e numa distância de penetração de $5 \mathrm{~mm}$, valores estes previamente fixados; Valores $\mathrm{L}^{*}, \mathrm{a}^{*}, \mathrm{~b}^{*}$, $\mathrm{h}^{\circ}$ e C* - utilizou-se um colorímetro marca Minolta, modelo CR 400, com iluminante $\mathrm{D}_{65}$ no sistema de cor CIEL*a*b*. As leituras dos valores $\mathrm{L}^{*}, \mathrm{a} * \mathrm{e}$ b* foram feitas em lados opostos na região equatorial do pirênio inteiro e diretamente na superfície do pequi fatiado colocado em placa de petri. $\mathrm{O}$ valor $\mathrm{L}^{*}$ indica quão claro ou quão escuro é o produto, variando de zero (totalmente preto) a cem (totalmente branco). A coordenada de cromaticidade $a^{*}$ varia de verde a vermelho, correspondendo a valores negativos e positivos, respectivamente. A coordenada de cromaticidade $b^{*}$ varia de azul a amarelo, correspondendo a valores negativos e positivos, respectivamente. Os valores $\mathrm{a}^{*} \mathrm{e} \mathrm{b}^{*}$ foram usados para calcular o ho (ângulo de tonalidade ou ângulo de cor) e o C* (cromaticidade) (descreve a intensidade de uma tonalidade de cor) usando-se as seguintes fórmulas: $\mathrm{h}^{0}=\tan ^{-1}\left(\mathrm{~b}^{*} / \mathrm{a}^{*}\right)$ e $\mathrm{C}^{*}=\left(\mathrm{a}^{* 2}+\mathrm{b}^{* 2}\right)^{1 / 2}$, respectivamente; Carotenoides totais (mg por 100g) - foram extraídos com hexano, sendo a cor lida em espectrofotômetro a 450nm (IAL, 1985); â-caroteno (mg por 100g) - extraído com acetona:hexano (4:6) e determinado segundo NAGATA \& YAMASHITA(1992). O teor de ß-caroteno

Ciência Rural, v.42, n.5, mai, 2012. 
foi expresso em miligrama por $100 \mathrm{~g}$, após o seu equacionamento: $ß$-caroteno $=0,216 \mathrm{~A}_{663}-1,22 \mathrm{~A}_{645}$ $0,304 A_{505}+0,452 A_{453}$, sendo: $A_{663}, A_{645}, A_{505}$ e $A_{453}$, leituras de absorbância nos respectivos comprimentos de onda; Vitamina C (mg de ácido ascórbico por 100g) - determinado pelo método colorimétrico, utilizando-se 2,4 dinitrofenilhidrazina, segundo STROHECKER \& HENNING (1967); Índice de peróxidos ( $\mu$ g de oxigênio por grama de lipídeos) - a extração dos peróxidos foi realizada utilizando-se solução de ácido acético com clorofórmio (3:2) e titulada com solução de tiossulfato de sódio 0,1N (IAL, 1985) e análises microbiológicas (Coliformes a $35^{\circ} \mathrm{C}$ e a $45^{\circ} \mathrm{C}$ (NMP por g de polpa) e Pesquisa de Salmonella sp. - foram realizadas segundo a ICMSF (1982) e SILVA et al. (1997).

\section{RESULTADOS E DISCUSSÃO}

As variáveis pH e acidez titulável não foram afetadas significativamente pela interação entre os fatores corte e tempo de armazenamento e nem pelo efeito isolado desses fatores. O valor médio de $\mathrm{pH}$ e acidez titulável em pequi congelado foi 7,29 e 0,76mL de $\mathrm{NaOH} 0,01 \mathrm{~N}$, respectivamente. TAVARES et al.(1998) também não observaram variações nos valores de acidez titulável e pH em acerola, ao estudar a eficiência do congelamento em câmara e em túnel.

Normalmente, os ácidos orgânicos tendem a diminuir no decorrer do armazenamento, à medida que são respirados ou convertidos a açúcares (CHITARRA \& CHITARRA, 2005), entretanto, o emprego do congelamento seguido de armazenamento refrigerado pode ser utilizado para explicar a não ocorrência de redução nos teores desses ácidos, uma vez que a redução na temperatura tem sido o método mais utilizado e mais eficiente para manter a qualidade das frutas e prolongar seu período de comercialização (KLUGE et al., 2002). Segundo HARDENBURG et al. (1986), o armazenamento refrigerado retarda o amadurecimento, o amaciamento, as mudanças na coloração e na textura, as mudanças metabólicas indesejáveis, a perda de massa e o crescimento microbiano.

Os teores de sólidos solúveis foram influenciados significativamente pelos fatores corte e tempo de armazenamento, isoladamente. O pequi congelado inteiro apresentou maiores teores de sólidos solúveis $\left(9,73^{\circ}\right.$ Brix) em relação ao fatiado $\left(9,03^{\circ}\right.$ Brix). O fatiamento do mesocarpo interno do pequi promoveu perda de sólidos solúveis por meio do rompimento celular. Os teores de sólidos solúveis do pequi congelado diminuíram linearmente durante o armazenamento (Figura 2A), devido, possivelmente, à perda de fluidos durante o congelamento e descongelamento. MELO et al. (2000) também verificaram decréscimo nos teores de sólidos solúveis em pitangas maduras mantidas sob congelamento ($18^{\circ} \mathrm{C}$ ) durante 90 dias.

O tempo de armazenamento influenciou significativamente na firmeza dos pequis. Observouse redução linear nos valores de firmeza do pequi congelado ao longo de doze meses de armazenamento (Figura 2B). A perda de firmeza em frutos que são submetidos ao congelamento ocorre devido aos cristais de gelo que podem perfurar as paredes e membranas celulares, permitindo a reação entre enzimas e substratos, acelerando assim o rompimento de células e o desenvolvimento de danos, incluindo mudanças físicas de textura e cor, sensoriais e outras (CARNEIRO \& CAL-VIDAL, 1998). De acordo com estes mesmos autores, dois mecanismos podem promover o dano à estrutura celular e conduzir diretamente à diminuição da firmeza do vegetal. O primeiro está relacionado com a possibilidade de perfuração do tecido vegetal pelo gelo intracelular, que contribui para a redução da pressão de turgor. $\mathrm{O}$ segundo relaciona-se com a quebra da estrutura da parede celular abrindo caminho para o colapso celular.

$\mathrm{O}$ valor $\mathrm{L}^{*}$ foi afetado significativamente somente pelo fator corte. O pequi congelado na forma inteira apresentou maior valor $L^{*}(67,19)$, indicando menor escurecimento do mesocarpo interno deste produto quando comparado com o fatiado $(65,62)$.

O tempo de armazenamento afetou significativamente o valor $\mathrm{a}^{*}$ do pequi congelado. Observou-se redução nesse valor até o sexto mês e tendência de estabilização até o final do armazenamento (Figura 2C), indicando redução da cor vermelha, uma vez que o valor a* varia de verde (valores negativos) a vermelho (valores positivos), sugerindo que o processo metabólico envolvido nesta mudança de cor pode ser a degradação dos carotenoides, que conferem pigmentação que variam do amarelo ao vermelho.

$\mathrm{O}$ valor $\mathrm{b}^{*}$ foi influenciado significativamente pelos fatores corte e tempo de armazenamento, isoladamente. $\mathrm{O}$ valor $\mathrm{b}^{*}$ do pequi congelado na forma fatiada foi menor $(61,83)$ em relação ao valor b* do pequi congelado inteiro $(63,29)$ (Figura 2D). Menores valores de $b^{*}$ em pequi congelado na forma fatiada ao longo do tempo indicam que houve uma diminuição da coloração amarela desses produtos, sugerindo decréscimo no teor de carotenoides que conferem a coloração amarelo-alaranjada (ALVES et al., 2010). Assim, a redução na cor amarela aconteceu, provavelmente, devido à degradação de ß-caroteno, principal pigmento responsável pela coloração do mesocarpo interno do pequi (VILAS BOAS, 2004). 


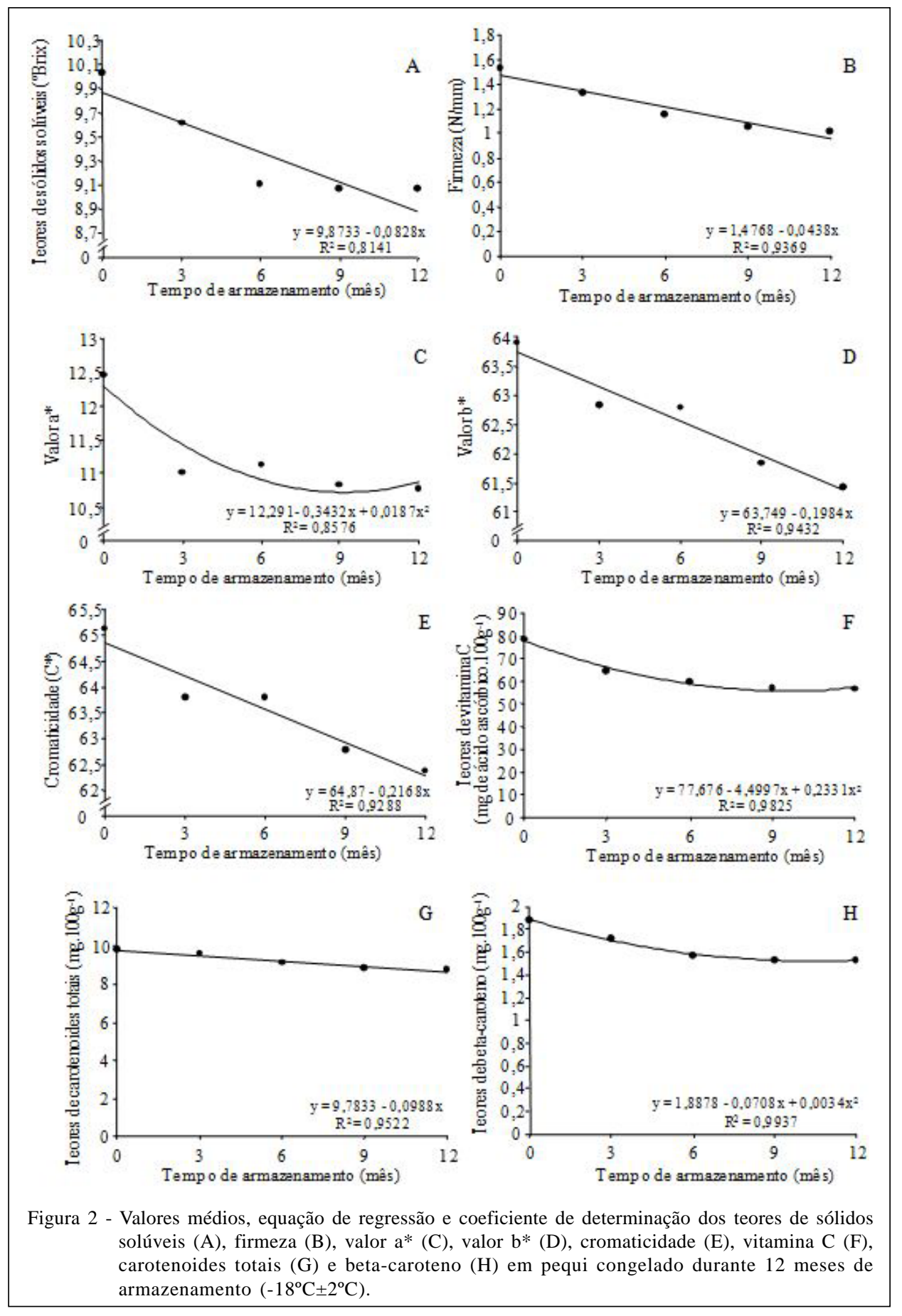

O ângulo de cor ou tonalidade de cor ( $\mathrm{h}^{\circ}$ ) é a grandeza, em graus, que caracteriza a qualidade da cor (azul, vermelho, verde, etc.), permitindo diferenciála. $\mathrm{O} h^{\circ}$ não foi afetado significativamente pela interação entre os fatores corte e tempo de armazenamento e nem houve efeito isolado desses fatores. O valor médio do $\mathrm{h}^{\circ}$ do pequi congelado foi de $79,8^{\circ}$, correspondente à cor amarelo-avermelhado, que não sofreu alterações durante 12 meses de armazenamento.

A variável cromaticidade $\left(C^{*}\right)$ foi influenciada significativamente pelos fatores corte e tempo de armazenamento, isoladamente. O C* indica a intensidade de uma tonalidade de cor, quanto maior o valor de $\mathrm{C}^{*}$ mais intensa a cor. O pequi congelado 
inteiro apresentou coloração mais intensa $(64,31)$ em relação ao fatiado $(62,83)$.

Observou-se decréscimo linear na intensidade de cor do pequi congelado durante o armazenamento por 12 meses (Figura 2E), indicando perda da intensidade de cor, devido, possivelmente, a alterações nos carotenoides.

De acordo com os resultados de cor, observa-se que houve redução na cor amarela e vermelha do pequi congelado durante o armazenamento sem alterar a sua tonalidade de cor amareloavermelhado, apresentando apenas variação na intensidade desta cor. Quanto à diminuição de sua intensidade, esta pode ser atribuída à degradação de pigmentos carotenoides, os quais diminuíram ao longo do armazenamento. A alteração da cor do pequi congelado provocada pelo armazenamento também foi observada por GONÇALVES et al. (2010).

Os teores de vitamina $\mathrm{C}$ foram afetados significativamente pelos fatores corte e tempo de armazenamento, isoladamente. $O$ pequi congelado na forma fatiada apresentou menores teores de vitamina C (60,44mg de ácido ascórbico por $100 \mathrm{~g})$, quando comparado ao congelado inteiro $(66,09 \mathrm{mg}$ de ácido ascórbico por 100g).

Observou-se redução acentuada nos teores de vitamina $C$ em pequi congelado até o sexto mês de armazenamento, em seguida, houve tendência de estabilidade nestes teores (Figura 2F). GONÇALVES et al. (2010) também observaram decréscimo nos teores de vitamina $\mathrm{C}$ ao longo de 6 meses de armazenamento nos dois métodos de congelamento, embora o método por ar forçado tenha se mostrado melhor na retenção desta vitamina do que o ar estático.

A determinação do conteúdo de ácido ascórbico em vegetais é muito importante, pois, além de seu papel fundamental na nutrição humana (GUTHRIE, 1989), sua degradação pode favorecer o escurecimento não enzimático (ALLAH \& ZAKI, 1974) e causar aparecimento de sabor estranho (BERNHARDT et al., 1979). Além disso, o ácido ascórbico é um importante indicador, pois sendo a vitamina mais termolábil, sua presença no alimento, indica que, provavelmente, os demais nutrientes também estão sendo preservados (BENDER, 1978; ÖZKAN et al., 2004)

Os teores de carotenoides totais e $\beta$ caroteno foram afetados significativamente somente pelo fator tempo de armazenamento. Observou-se redução linear nos teores de carotenoides totais em pequi congelado durante 12 meses de armazenamento (Figura 2G) e diminuição nos teores de $\beta$-caroteno até o sexto mês, em seguida, houve tendência de estabilização até o final (Figura 2H). Esses resultados são condizentes com a redução dos valores $\mathrm{a}^{*} \mathrm{e}$ b* (Figura 2C e 2D), relativos à cor vermelha e amarela, respectivamente, e da intensidade de cor (amareloavermelhado) (Figura 2E) do pequi congelado durante 12 meses de armazenamento, podendo relacionar esta diminuição à degradação de carotenoides.

O resultado encontrado neste trabalho está coerente com o observado por OLIVEIRA et al. (2006) em pequi submetido ao congelamento em nitrogênio líquido e diretamente em freezer, que verificaram teores de carotenoides de 11,07 e $11,34 \mathrm{mg}$ por $100 \mathrm{~g}$, respectivamente, após seis meses de armazenamento. Estes autores não verificaram diferença significativa entre esses dois métodos de congelamento em relação aos teores de carotenoides.

O principal atributo de qualidade avaliado pelo consumidor durante a aquisição de um produto é a aparência, incluindo a cor. Desse modo, a preservação dos carotenoides do pequi durante o processamento e armazenamento é de fundamental importância.

Devido ao seu alto teor de lipídeos, o pequi torna-se suscetível ao processo de rancidez oxidativa quando armazenado de forma inadequada. Os pequis congelados, tanto inteiros quanto em fatias, não sofreram o processo de peroxidação lipídica durante 12 meses de armazenamento.

Neste experimento, não foi constatada a presença de coliformes a $35^{\circ} \mathrm{C}$ e a $45^{\circ} \mathrm{C}$ e nem a presença de Salmonella sp. em 25 g de pequi congelado, inteiro e fatiado, durante 12 meses de armazenamento. Esses resultados estão de acordo com o padrão microbiológico especificado na Resolução da Diretoria Colegiada (RDC) ํㅜㄹㄹ de 02 de janeiro de 2001, que especifica um limite máximo tolerado para coliformes a $45^{\circ} \mathrm{C}$ de $5 \times 10^{2} \mathrm{NMP} \mathrm{g}^{-1}$ e ausência de Salmonella sp. em $25 \mathrm{~g}$ para frutas, produtos de frutas e similares: "frescos, in natura, preparados (descascados ou selecionados ou fracionados), sanificados, refrigerados ou congelados, para consumo direto" (BRASIL, 2001). Desse modo, os pequis congelados nas formas inteira e fatiada se encontram adequados para o consumo, uma vez que estão de acordo com a legislação vigente.

Pode-se evidenciar a importância do uso de matéria-prima de qualidade e de condições higiênicosanitárias satisfatórias do local de processamento e armazenamento, além do respeito à cadeia de frio e da adoção de boas práticas de fabricação, permitindo assim a oferta de um produto seguro do ponto de vista microbiológico e com qualidade sensorial e nutricional ao consumidor.

\section{CONCLUSÃO}

O tempo de armazenamento de 12 meses determina redução nos teores de sólidos solúveis, nos valores de firmeza, nos valores $\mathrm{a}^{*}, \mathrm{~b}^{*} \mathrm{e} \mathrm{C}^{*}$ e nos teores 
de carotenoides totais, $ß$-caroteno e vitamina $\mathrm{C}$ em pequi congelado, independentemente do corte usado. $\mathrm{O}$ pequi congelado não sofre alterações no $\mathrm{pH}$, nos teores de acidez titulável e na tonalidade de cor $\left(\mathrm{h}^{\circ}\right)$. Pequis congelados nas formas inteira e fatiada são considerados seguros microbiologicamente durante 12 meses de armazenamento $\left(-18^{\circ} \mathrm{C} \pm 2^{\circ} \mathrm{C}\right)$.

De modo geral, pode-se concluir que a qualidade de pequis fatiados e inteiros, entendida sob os aspectos nutricionais e microbiológicos, pode ser preservada à temperatura de $-18^{\circ} \mathrm{C}\left( \pm 2^{\circ} \mathrm{C}\right)$ por 12 meses, desde que obedecidas à cadeia de frio e às boas práticas de fabricação.

\section{AGRADECIMENTOS}

Os autores agradecem à Fundação de Amparo à Pesquisa do estado de Minas Gerais (FAPEMIG), pela concessão da bolsa de pós-doutorado a primeira autora e pelo apoio financeiro ao projeto; ao Conselho Nacional de Desenvolvimento Científico e Tecnológico (CNPq) e à Coordenação de Aperfeiçoamento de Pessoal de Nível Superior (CAPES).

\section{REFERÊNCIAS}

ALLAH, M.A.A.; ZAKI, M.S.A. Preservation of mango juice by freezing and canning. Food / Nahrung, Weinheim, v.18, p.207-216, 1974. Disponível em: <http://onlinelibrary.wiley.com/ doi/10.1002/food.19740180212/pdf>. Acesso em: 10 nov 2010.

ALVES, J.A. et al. Vida útil de produto minimamente processado composto por abóbora, cenoura, chuchu e mandioquinha-salsa. Ciência e Agrotecnologia, Lavras, v.34, n.1, p.182-189, 2010. Disponível em: <http://dx.doi.org/10.1590/S141370542010000100022>. Acesso em: 24 ago. 2011.

ALVES, R.E. Qualidade de acerola submetida à diferentes condições de congelamento, armazenamento e aplicação pós-colheita de cálcio. 1999. 117f. Tese (Doutorado em Ciência dos Alimentos) - Universidade Federal de Lavras, Lavras, MG.

AOAC - Association Of Official Analytical Chemists. Official methods of analysis of the association of Official Analytical Chemistry. 17.ed. Washington, 2002. 1410p.

BENDER, A.E. Food processing and nutrition. London: Academic, 1978. 243p.

BERNHARDT, L.W. et al. Mudanças que ocorrem durante o armazenamento de frutas e hortaliças congeladas. Boletim do Instituto de Tecnologia de Alimentos, Campinas, v.16, p.934, 1979.

BRASIL. Ministério da Saúde. Agência Nacional de Vigilância Sanitária. Resolução da diretoria colegiada (RDC) $n^{\circ} 12$, de 02 jan. 2001. Regulamento técnico sobre os padrões microbiológicos para alimento. Disponível em: <http:// www.anvisa.gov.br/legis/resol/12_01rdc.htm>. Acesso em: 04 jan. 2010.

CARNEIRO, C.S.; CAL-VIDAL, J. Ice crystal structuring as affected by amphiphilic substances. Journal of Scanning Microscopies, Mahwah, v.20, n.3, p.244-246, 1998.
CHITARRA, M.I.F.; CHITARRA, A.B. Pós-colheita de frutos e hortaliças: fisiologia e manuseio. Lavras: UFLA, 2005. 785p.

FERREIRA, D.F. Análises estatísticas por meio do SISVAR para windows versão 4.0. In: REUNIÃO ANUAL DA REGIÃO BRASILEIRA DA SOCIEDADE INTERNACIONAL DE BIOMETRIA, 45., 2000, São Carlos. Programa e Resumo... São Carlos: UFSCar, 2000. p.235.

GONÇALVES, G.A.S. et al. Qualidade do pequi submetido ao cozimento após congelamento por diferentes métodos e tempos de armazenamento. Revista Ceres, Viçosa, v.57, n.5, p.581588, 2010. Disponível em: <http://www.ceres.ufv.br/ceres/ revistas/V57N005P10209.pdf>. Acesso em: nov. 2010.

GUTHRIE, H.A. Introductory nutrition. 7.ed. Saint Louis: Mosby, 1989. 394p.

HARDENBURG, R.E. et al. The comercial storage of fruits, vegetables, and florist and nursery stocks. Beltsville: USDA, 1986. 130p.

IAL - Instituto Adolfo Lutz. Normas analíticas, métodos químicos e físicos para análise de alimentos. 3.ed. São Paulo: Instituto Adolfo Lutz, 1985 . V.1, 533p.

ICMSF (INTERNATIONAL COMMISSION ON MICROBIOLOGICAL SPECIFICATIONS FOR FOODS). Microorganisms in foods. 2.ed. Toronto: University of Toronto, 1982. 436p.

KLUGE, R.A. et al. Fisiologia e manejo pós-colheita de frutas de clima temperado. Campinas: Rural, 2002. 214p.

MELO, E. de A. et al. Temperatura no armazenamento de pitanga. Scientia Agricola, Piracicaba, v.57, n.4, p.629-634, 2000. Disponível em: <http://dx.doi.org/10.1590/S010390162000000400006>. Acesso em: 7 nov. 2010.

NAGATA, M.; YAMASHITA, I. Simple method for simultaneous determination of chlorophyll and carotenoids in tomato fruit. Nippon Shokuhin Kogyo Gakkaishi, Tokyo, v.39, n.10, p.925-928, 1992.

OLIVEIRA, M.N.S. et al. Estádio de maturação dos frutos e fatores relacionados aos aspectos nutritivos e de textura da polpa de pequi (Caryocar brasiliense Camb.). Revista Brasileira de Fruticultura, Jaboticabal, v.28, n.3, p.380386, 2006. Disponível em: <http://dx.doi.org/10.1590/S010029452006000300009>. Acesso em: 20 nov. 2010.

ÖZKAN, M. et al. Effects of hydrogen peroxide on the stability of ascorbic acid during storage in various fruit juices. Food Chemistry, Chicago, v.88, n.4, p.591-597, 2004. Disponível em: <http:// www.sciencedirect.com/science/article/pii/S0308814604001633. Acesso em: 26 ago. 2011. doi:10.1016/j.foodchem.2004.02.011.

SILVA, N. et al. Manual de métodos de análise microbiológica de alimentos. São Paulo: Varela, 1997. 295p.

STROHECKER, R.; HENNING, H.M. Analisis de vitaminas: metodos comprobados. Madrid: Paz Montalvo, 1967. 428p.

TAVARES, J.C. et al. Métodos de congelamento na conservação da acerola (Malpighia emarginata DC.). Caatinga, Mossoró, v.11, p.71-74, 1998.

VILAS BOAS, E.V. de B. Frutas minimamente processadas: pequi. In: ENCONTRO NACIONAL SOBRE PROCESSAMENTO MÍNIMO DE FRUTAS E HORTALIÇAS, 3., 2004, Viçosa. Palestras, Resumos e Oficinas... Viçosa: UFV, 2004. p.122-127. 